there is little danger of data becoming out of date while the book is in press.

Much of the contents will be of value to the student at this stage. The book has nineteen chapters, and, in addition to stock material which every such textbook must include, there are chapters on the quantum theory, the structure of crystals, the wave mechanics, cosmic radiation and the positron and meson, and relativity.

The two chapters on gaseous conduction and dis. charge, compared with other text-books, are considerably abbreviated. This is reasonable provided that the student is not led to think that a given subject is quite cleaned up when in fact it is still in a confused state. The paragraphs on recombination are somewhat misleading in this respect. Also the original method of deriving an equation for sparking potential due to Townsend is given. But it is now generally held that ionization by positive ions in weak fields is very improbable and that secondary emission from the cathode must be invoked instead to explain the maintenance of discharge. An equation agreeing equally well with experiment can be derived on these lines.

In Chapter 3 the introduction of a recent precision method of determining $e / m$ is welcome, as well as the summary of measurements of Avagadro's constant. Similarly, the chapter on positive rays is good, though Fig. vii referred to in the text is not included in the plate.

In a short chapter on the quantum theory, proofs are given of Planck's equation, Debye's expression for specific heats, as well as the Bohr hydrogen atom. Since the book is based on experience of lectures on these lines in Manchester, one must conclude that this abbreviated treatment of black-body radiation and specific heats has been found to be successful. I myself would have been content with a more descriptive summary at this stage with emphasis on experimental results, leaving the full theoretical treatment for one bite in the following year. But this is merely an individual view, and the volume loses no interest through provoking this type of comment.

In Chapter 6, on the thermionic effect, one welcomes a descriptive reference to the modern theory of electronic states in solids. It is right and proper that students should realize that these concepts can be applied to metals and insulators, with which they are so familiar in the laboratory, as well as to atoms. But students may be puzzled by the integral on p. 110 as the text is worded. It is also questionable whether the 'shot' effect could ever give a precision value of electronic charge. The experimental values so far obtained show wide divergences. In the chapter on atomic spectra the author can speak with special authority. The student will find it tough going and is called upon to accept a number of statements without proof. But with the exception of the Zeeman effect, to which surprisingly scant reference is made, the meat is all there for the good student prepared to dig into it.

The chapters on X-rays and the structure of crystals contains much useful information, and in the next chapter student readers are introduced to the difficult subject of wave mechanics. It is to be hoped that they will complete the chapter still imbued with humility, and not be tempted to talk glibly about it. But the statement of the conditions under which Schrödinger's equation can be solved (p. 199) requires correction.

The greater part of the remainder of the book is taken up with radioactivity and the nucleus. The material is up to date and well selected, and students will read it with interest, not only because so much of it is experimental in background and therefore not difficult to grasp at this stage in their mathematical training, but also exciting. Having got them into this atmosphere, the author pulls them up sharply by a concluding chapter on relativity.

In brief, the selection of material is interesting and in many respects novel. But the book shows signs of hurried writing. There are a number of errata which have not caught the eye of the proof readers, and should have been added to the list on p. 1. Here and there the text is also rather loose. But the task of writing it under the pressure of present conditions calls for some allowance in such matters, and one may anticipate a new edition at an early date with emendations.

A. M. Tyndall.

\section{ADVANCES IN MEDICINE}

\section{The March of Medicine}

(New York Academy of Medicine : Lectures to the Laity, No. 6, 1941.) Pp. xiv+154. (New York: Columbia University Press; London: Oxford University Press, 1941.) 13s. 6d. net.

\section{7} HIS volume contains six lectures devoted respectively to : humanism and science, by Dr. Alan Gregg, director for the medical sciences, Rockefeller Foundation; Paracelsus in the light of four hundred years, by Dr. Henry E. Sigerist, director of the Institute of History of Medicine, Johns Hopkins University; psychiatry and the normal life, by Dr. William Healy, director of the Judge Baker Guidance Centre, Boston; philosophy as therapy, by Dr. Irwin Edman, professor of philosophy, Columbia University; the promise of endocrinology, by Dr. Oscar Riddle, Department of Genetics, Carnegie Institution of Washington; and "What we know about Cancer", by Dr. Francis Carter Wood, director of the Laboratories, St. Luke's Hospital, New York City.

Dr. Gregg maintains that humanism offers much to science and especially medical science on the occasions when the physician finds science inadequate for the patient's needs and should call in the help of literature and the arts. Dr. Sigerist declares that while Paracelsus's contributions to medicine were of a totally different kind from those of the other great physicians and surgeons of the Renaissence, he made a number of valuable contributions to medicine, particularly as regards treatment, into which he introduced many chemical remedies. According to Dr. Healy, the time is ripe for psychiatry to take a lead in educating the normal man to know more about himself "for the sake of his own selfdirection in social interrelationships". Dr. Edman, while not asserting that philosophy is a substitute for medicine, logic for surgery, or ethics for antiseptics, declares that philosophy is therapeutic in the sense that it is both sedative and stimulant, while the good physician is a kind of family and social philosopher. Dr: Riddle foretells that in the future endocrinology will add to human eificiency, normality, understanding and health. In conclusion, Dr. Wood shows that an enormous advance has been made in the treatment of cancer, especially in early cases, owing to the technical developments of surgery and the discovery of the destructive effects of radium and $\mathrm{X}$-rays upon malignant tissue. 